\title{
A NEW SPECIES OF WHIP-SPIDER (PHRYNICHIDAE: AMBLYPYGI) FROM ANDHRA PRADESH, INDIA
}

\author{
D.B. Bastawade ${ }^{1}$, K. Thulsi Rao ${ }^{2}$, S.M. Maqsood Javed ${ }^{3}$ and I. Siva Rama Krishna ${ }^{3}$
}

\author{
1 Zoological Survey of India, Western Regional Station, Pune, Maharashtra, India \\ ${ }^{2,3}$ Ecological Research \& Monitoring Laboratories, Nallamalai Hill Ranges, Eastern Ghats, Project Tiger Circle, \\ Srisailam, Kurnool District, Andhra Pradesh 518102, India \\ Email: ${ }^{2}$ thulsirao@yahoo.co.in (corresponding author)
}

web supplement

\begin{abstract}
A new species of whip-spider (Phrynichidae: Amblypygi) is described from Eastern Ghats of Andhra Pradesh, India. Phrynichus andhraensis sp. nov. is compared with the known Indian species Phrynichus phipsoni Pocock. The new species has small body, yellowish-brown in colour, darker on carapace, closely granular on dorsum of carapace, abdomen and appendages. Chelicerae and pedipalps long and slender. Pedipalp bearing 32 spines in total, the distitibiae of IV leg with 33 trichobothria. Other morphological details of the new species are also given.
\end{abstract}

\section{KEYWORDS}

Amblypygi, Eastern Ghats, India, NagarjunasagarSrisailam Tiger Reserve, new species, Phrynichidae, Phrynichus andhraensis $s p$. nov., whip-spider

The Whip-spiders (Amblypygi) from Indian sub-continent are represented by a few species and were initially described by Pocock (1900). The amblypygids are spectacular animals with flat body, narrow constriction between carapace and abdomen. They are most secretive, raptorial with extremely long pedipalp with an exceptionally long, whip like modified first pair of legs. Recently Weygoldt (1996) has revised and updated the Amblypygid fauna from Asia and Africa under the family Phrynichidae. During the arachnid faunal survey of Nagarjunasagar-Srisailam Tiger Reserve of Andhra Pradesh, specimens were studied in detail for morphology and genitalia to conclude and describe as a new species Phrynichus andhraensis. The types are stored in the ERM Laboratory, Nagarjunasagar-Srisailam Tiger Reserve.

\section{Phrynichus andhraensis sp. nov.} (Figs. 1-9)

\section{Material Examined \\ Holotype: Female, 11.x.2004, Mamidisela (16004'N-78054'E), Nagarjunasagar-Srisailam Tiger Reserve, Kurnool district, Andhra Pradesh, India, coll. S.M. Maqsood Javed, ERM/AP/1, preserved in $70 \%$ alcohol, genitalia dissected and kept in separate vial along with the specimen.}

Paratype: 1 female, 21.xi.2004, Mallelathertham (16014'N-78049'E), Nagarjunasagar-Srisailam Tiger Reserve, Mahboobnagar district, Andhra Pradesh, India, coll. K. Thulsi Rao, ERM/AP/2, preserved in $70 \%$ alcohol.

\section{Etymology}

The specific Andhra is a noun in apposition taken from the the research team collected two mature female specimens. These

name of state from where the specimens were collected. This is being the first report of Amblypygi from Eastern Ghats of Andhra Pradesh.

\section{Diagnostic features}

Body colour yellowish-brown, darker on carapace, closely granular on dorsum of carapace, abdomen and appendages (Image $1^{\mathrm{w}}$ ). Chelicerae and pedipalps long and slender, all basitibiae II - IV with one segment each, distitibiae II - IV with 29, 32 and 33 trichobothria respectively (Fig. 8). Total body length $19.00 \mathrm{~mm}$; Carapace $7.00 \mathrm{~mm}$ long, $13.50 \mathrm{~mm}$ wide, abdomen $12.00 \mathrm{~mm}$ long, $7.50 \mathrm{~mm}$ wide.

\section{Female}

Holotype: Carapace, chelicerae and pedipalps yellowish-brown, black on ocular tubercles and darker on palpal edges, yellowish on tergites, sternites and legs I - IV, but clear yellow on joints at basitarsi - distitarsi and the tips of legs I.

Carapace: Almost twice wider than long, sparsely granular but mixed with coarse and fine granules. Anterior margin is almost straight and smooth in the middle portion. Deeply notched laterally at ocular region, turned roundish into lateral granular margin and continued as posterior margin, deeply incised in the middle $1 / 3$ portion. Sulcus distinct, deep, roughly ' $T$ ' shaped and bordered with granular margin. A pair of median eyes situated almost on the middle of anterior margin and the eyes directed towards lateral side. Lateral eyes in triads, placed just behind the lateral notch on anterior margin, eyes directed anterior-lateral, extreme posterior lateral and posterior inner wards, no setae seen. Chelicera sparsely granular on dorsal and outer surface, smooth and thickly fringed with line of short and soft setae on ventral portion continued up to distal end. Outer surface also clothed with a few short pointed setae, but more setae present on ventral outer portion and continued up to distal end. Distal ventral portion armed with a double pointed tooth on inner margin of the fang groove and four teeth in a series on outer margin. First and second teeth placed together. Fang sharply pointed, deeply curved, almost $1 / 3^{\text {rd }}$ of basal segment and armed with five teeth in a series, progressively becoming smaller from proximal to distal. Inner and outer surfaces of fang also thickly fringed with a row of short and soft setae (Fig. 2).

Pedipalp long and slender, granular on trochanter, femur and

${ }^{w}$ See Images in the web supplement at www.zoosprint.org

(C) Zoo Outreach Organisation; www.zoosprint.org Manuscript 1361; Received 17 May 2005; Revised received 26 August 2005; Finally accepted 07 November 2005; Date of publication 21 November 2005 December 2005 ISSN 0973-2535 (Print edition); 0973-2551 (O nline edition) 

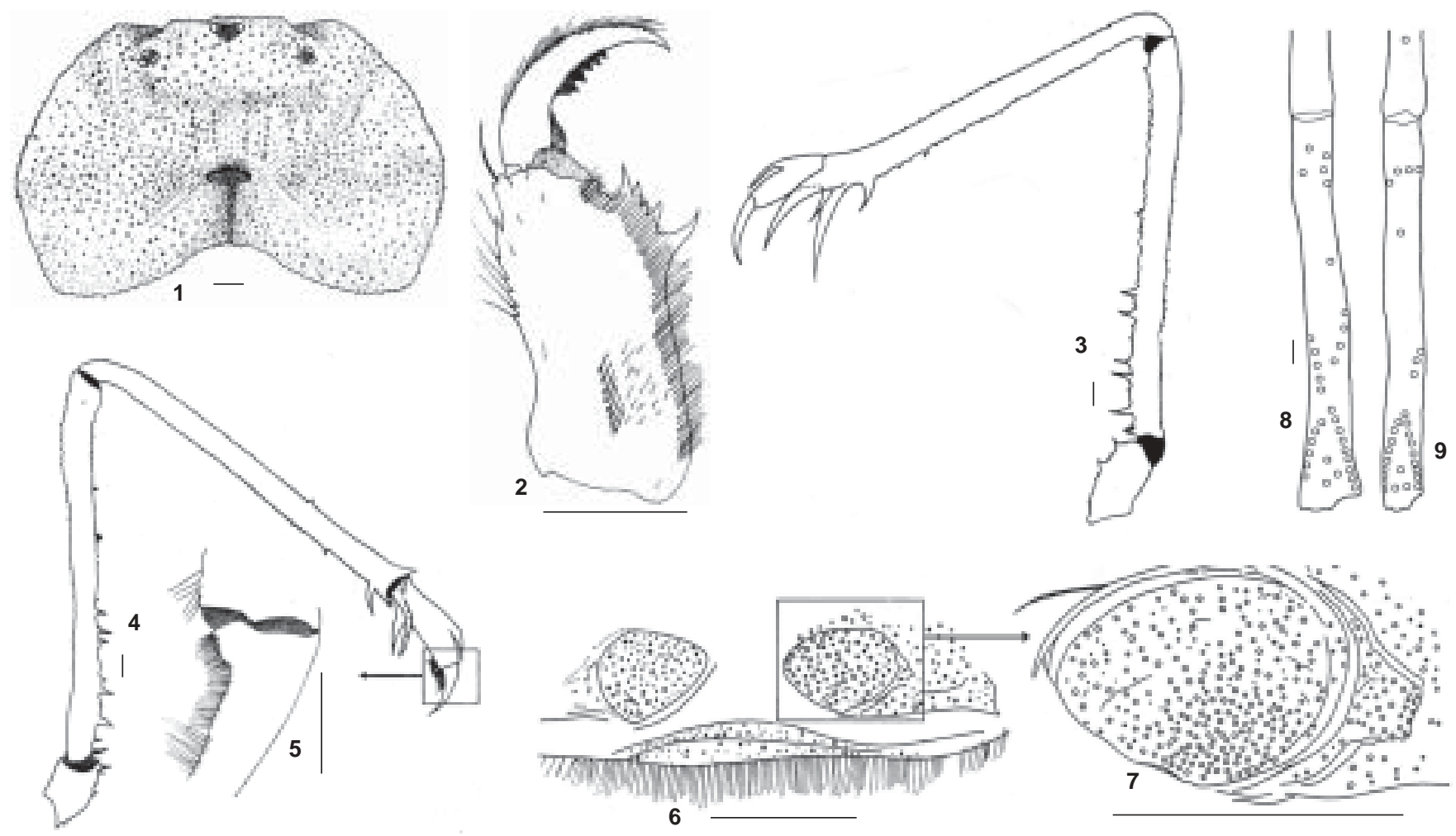

Figures 1-9. Phrynichus andhraensis sp. nov. Scale $=1 \mathrm{~mm}$

1 - Carapace, dorsal view (excluding chelicera); 2 - Chelicera, inner view; 3 - Pedipalp, dorsal view; 4 - Pedipalp, ventral view; 5 - Proximal portion of pedipalp tarsus (enlarged), ventral view; 6 - Female internal genitalia, dorsal view; 7 - Female genitalia gonopod (enlarged), dorsal view; 8 - Number and arrangement of trichobothria on distitibia of leg IV of Phrynichus andhraensis sp. nov. on exterior surface; 9 - Number and arrangement of trichobothria on distitibia of leg IV of Phrynichus phipsoni Pocock on exterior surface.

patella. Trochanter roundish on inner anterior margin, surface is granular and few granules bearing stout and sharply pointed setae, two anterior dorsal and two anterior ventral short, stout and pointed spines present. Femur is three times as long as carapace length. Anterior dorsal margin with three larger spines, proximal one longer than the distal two; three median spines, $2^{\text {nd }}$ distal being longest, five smaller spines, basal and $1^{\text {st }}$ being longest and distal being double (Fig. 3). Ventral inner margin with three longer spines, $2^{\text {nd }}$ being longest, one medium size on distal portion, four smaller spines, $3^{\text {rd }}$ being smallest. Patella as long as femur and three times as long as carapacial length and surface granular. Anterior dorsal margin with three distal spines, proximal one being shorter and distal two being much more long, bent, sharply pointed and sparsely and weakly denticulate on ventral surface, plus three to four weak, minor spines present. Anterior ventral margin with three spines, two on distal ventral end, longer and pointed, while the $3^{\text {rd }}$ placed on $2 / 3^{\text {rd }}$ distal portion, much smaller and weakly pointed (Fig. 4). Tibia slightly shorter than carapacial length, much shorter than either femur or patella and surface granular, but more granular on proximal than on distal portion with single dorsal and ventral spines, dorsal longer than ventral and placed more than half the length anteriorly, while ventral spine placed almost at the base and sparsely denticulate on inner or anterior margin. Tarsus spinulate, curved and sharply pointed, almost triangular at the base, acutely marginate on inner portion and lateral surface clothed with short and soft setae and the inner basal portion with a row of short curved setae (Fig. 3, 4 \& 5).

Legs I having short tibiae and tarsal with 31 and 71 smaller segments respectively, three distal tibial and one proximal and one distal tarsal segments whitish. Basitibiae II - IV single segmented and without trichobothria, distitibiae II - IV with 29, 32 and 33 trichobothria respectively and both basi and distitibiae II - IV ventrally lined with double row of spines throughout. Tarsi II - IV with four segments each, $3^{\text {rd }}$ segment always smallest to remaining, and each ventrally lined with double row of spines. Sternite tripartite, $1^{\text {st }}$ narrowed anteriorly into a long shaft, margins granular at the base and lined with short setae anteriorly, anterior tip armed with a pair of stout, long sharply pointed setae, 5 - 6 short stout setae present on shaft itself, posteriorly expanded with truncate posterior margin.

Abdomen: Tergite I smooth, tucked under the cephalothorax. Tergites II - VII granular, weakly granular on margins, each with a pair of roundish submedian impressions. Tergites VIII - IX smooth, smaller and turned downwards. Sternites I -VI smooth, wider than long with genitalia. Sternites III - VI each with a pair of roundish submedian impressions and granular. Sternites VII -VIII is smaller and smoother. Plural membrane is in many 
Table 1. Showing comparative morphological features of Phrynichus phipsoni Pocock and Phrynichus andhraensis sp. nov. (in $\mathrm{mm}$ )

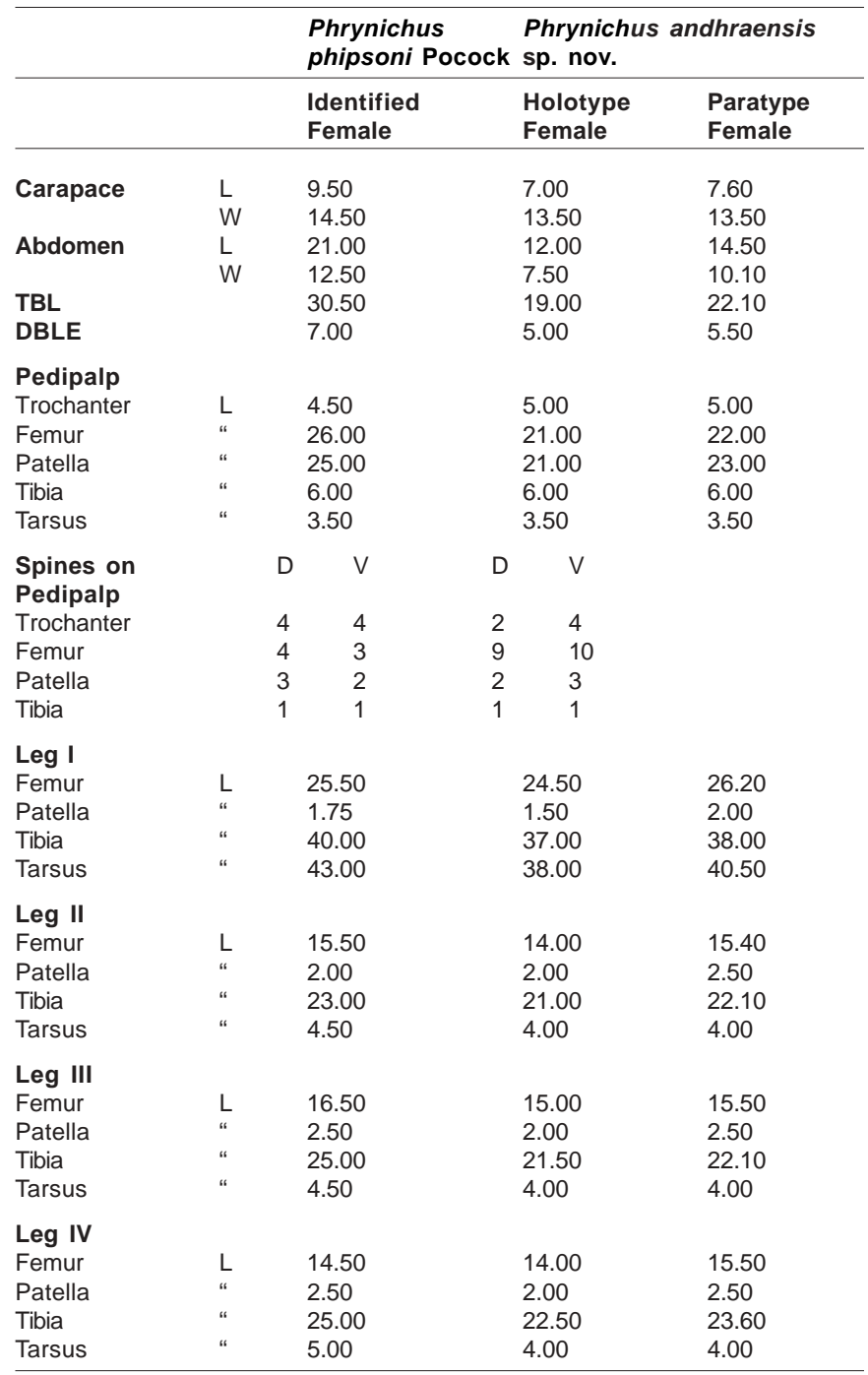

L - Length; W - Width; D - Dorsal side; V - Ventral side;

TBL - Total body length; DBLE - Distance between lateral eyes

folds with roundish tuberculate impressions on it. Sternite I smooth, sinulate medially on posterior margin and clothed with thick line of short and pointed bristles, sternite provided medially with genitalia, a pair of round gonopods placed on posterior portion. Surface of gonopods and near by areas covered with minute pores and each gonopod extends laterally into a conical portion, openings of ducts not visible dorsally (Figs. $6 \& 7$ ).

\section{Habitat}

The specimens were collected under tightly fixed medium sized stones near a perineal stream (Image $2^{\mathrm{w}}$ ) in the deep valley. The vegetation in the valley is canopied thickly with wild variety of tall mango trees (Mangifera indica) (Image $3^{\mathrm{w}}$ ). The source of stream was from the narrow cavities in a lime stone substratum. The neighbouring places have few lime stone narrow cavernicolous channels which remain wet throughout the year. The species Phrynichus phipsoni Pocock was recorded from human habitations and protected areas (Borkar et al. in press); where as Phrynichus andhraensis sp. nov. is so far recorded only from the forested habitats.

\section{Discussion}

This species shows closeness to the known Indian species Phrynichus phipsoni Pocock, which was redescribed after Pocock by Bastawade (1995). However, it differs in the following characters:

(i) Body size, colour, granulations on carapace, femur and patella of pedipalp of both these species are comparatively different (Table 1 and description).

(ii) The structure and number of spines on trochanter, femur, patella and tibia of the pedipalp of both these species are also different (Table 1).

(iii) The number of trichobothria on distitibiae of II-IV pair of leg with 29, 32 and 33 in Phrynichus andhraensis sp. nov., where as 29, 31 and 29 in Phrynichus phipsoni Pocock (Fig. 8 \& 9).

(iv) A pair of female genital gonopods differs in size, shape and minute pores covering the gonopod surface (Figs. $6 \& 7$ ).

\section{REFERENCES}

Bastawade, D.B. (1995). Redescription of Phrynichus phipsoni (Pocock) (Phrynichidae: Arachnida) collected after $100 \mathrm{yrs}$ from new locations in Maharashtra, western India. Journal of the Bombay Natural History Society 92: 132-136.

Borkar, M.R., N. Komarpant and D.B. Bastawade (in press). First report of Whip-spider Phrynichus phipsoni Pocock from human habitations and protected areas of Goa state, India, with notes on habits and habitats. Records of the Zoological Survey of India, Kolkata.

Pocock, R.I. (1900). Fauna of British India, Arachnida. Taylor and Francis, London, 279pp.

Weygoldt, P. (1998). Revision of the species of Phrynichus Karsch, 1879 and Euphrynichus Weygoldt, 1995 (Chelicerata, Amblypygi). Zoologica Stuttgart 147: 1-65.

\section{ACKnowledgement}

The authors are very much thankful to Sri S.K. Das IFS, Principal Chief Conservator of Forests, Sri Hitesh Malhotra, IFS, Addl. Principal Chief Conservator of Forests (WL), Sri A.V. Joseph IFS, Chief Conservator of Forests (WL), Andhra Pradesh and M. Sudhakar, IFS, Conservator of Forests \& Field Director, Project Tiger for constant encouragement and sustained support. We are also grateful to Dr. Rajesh Gopal, IFS, Inspector General of Forests and Director Project Tiger and the MoEF, New Delhi, for their consistent funding support and encouragement. We gratefully acknowledge our thanks to Dr. J.R.B. Alfred, Director, ZSI, Kolkata and Dr. Anil S. Mahabal, Scientist-E and Officer-in-Charge, Z.S.I, WRS, Pune for extending facilities. We wish to acknowledge V. Madhusudhan Reddy, Computer operator, E.R.M. Labs, Project Tiger, Srisailam, Andhra Pradesh. 